\title{
The power of seaweeds as plant biostimulants to boost crop production under abiotic stress
}

\author{
Ayodeji Deolu-Ajayi ${ }^{1}$, Ingrid van der Meer $^{1}$, Adrie Van der Werf $^{1}$, and Rumyana Karlova ${ }^{1}$ \\ ${ }^{1}$ Wageningen University \& Research
}

September 25, 2021

\begin{abstract}
In order to meet increasing food demands in the future, we will need to improve the current crop productivity. Abiotic stresses like drought and salinity are major factors resulting in crop yield losses and soil degradation worldwide. Recent studies suggest that seaweed-based biostimulants could be a solution for this problem. Here we summarise the current findings of using these biostimulants and highlight current knowledge gaps. Seaweed extracts were shown to enhance nutrient uptake and improve growth performance in crops under stressed and normal conditions. Seaweed extracts contain phytohormones, polysaccharides, polyphenols, lipids, amino acids and proteins. Although it has been shown that some of these compounds are active and have growth-promoting properties on plants, their underlying molecular mechanism of action and optimal applications especially in crops exposed to abiotic stress remains understudied. Seaweed extracts were shown to also improve protein content of crops and contribute to a healthy soil by facilitating water retention, soil aeration and nutrient availability, thereby promoting plant growth. In this paper we review the role of these extracts and their bioactive compounds as plant biostimulants. The targeted application to improve crop performance and the impact of seaweed extracts for enhancing the protein content of crops are discussed.
\end{abstract}

\section{Running title: The power of seaweeds}

\section{Review paper}

Title: The power of seaweeds as plant biostimulants to boost crop production under abiotic stress

Ayodeji O. Deolu-Ajayi ${ }^{1 \mathrm{a}}$, Ingrid M. van der Meer ${ }^{1 \mathrm{~b}}$, Adrie van der Werf ${ }^{1 \mathrm{a}}$ and Rumyana Karlova $\mathrm{cc}^{1{ }^{*}}$

${ }^{1 a}$ Wageningen University and Research, 6708PB Wageningen, The Netherlands, Agrosystems Research, Plant Sciences Group, ayodeji.deolu-ajayi@wur.nl, and adrie.vanderwer@@wur.nl

${ }^{1 b}$ Wageningen University and Research, 6708PB Wageningen, The Netherlands, Bioscience, Plant Sciences Group, ingrid.vandermeer@wur.nl

${ }^{1 c}$ Wageningen University and Research, 6708PB Wageningen, The Netherlands, Laboratory of Plant Physiology, Plant Sciences Group. rumyana.karlova@wur.nl

*Correspondence: rumyana.karlova@wur.nl (R. Karlova).

www.pph.wur.nl

\section{Keywords}

Abiotic stress, mechanism of action, protein transition, plant growth and development, seaweed biostimulants, sustainable agriculture.

Abstract 
In order to meet increasing food demands in the future, we will need to improve the current crop productivity. Abiotic stresses like drought and salinity are major factors resulting in crop yield losses and soil degradation worldwide. Recent studies suggest that seaweed-based biostimulants could be a solution for this problem. Here we summarise the current findings of using these biostimulants and highlight current knowledge gaps. Seaweed extracts were shown to enhance nutrient uptake and improve growth performance in crops under stressed and normal conditions. Seaweed extracts contain phytohormones, polysaccharides, polyphenols, lipids, amino acids and proteins. Although it has been shown that some of these compounds are active and have growth-promoting properties on plants, their underlying molecular mechanism of action and optimal applications especially in crops exposed to abiotic stress remains understudied. Seaweed extracts were shown to also improve protein content of crops and contribute to a healthy soil by facilitating water retention, soil aeration and nutrient availability, thereby promoting plant growth. In this paper we review the role of these extracts and their bioactive compounds as plant biostimulants. The targeted application to improve crop performance and the impact of seaweed extracts for enhancing the protein content of crops are discussed.

\section{Introduction}

\section{Closing yield gaps}

In the future our world will face two major problems: climate change and a growing world population. Estimated global population is expected to reach 10 billion in 2050 (UN DESA, 2017) and with rising temperatures, more desiccation and salinisation will be observed with negative consequences on crop growth and productivity worldwide (Mueller et al. , 2012). The substantial increase in food demand must be met while decreasing agriculture's global environmental footprint, and at the same time when agriculture is already challenged due to climate change.

Combining this with a global shift to a more animal-based diet (Henchionet al. , 2014), a higher crop productivity worldwide is needed with an important focus on increased plant protein production. The global demand for animal source food is expected to increase by over $70 \%$ in 2050 , not only because of the growing world population but also due to increased welfare (Alexandratos and Bruinsma, 2012). With increasing welfare the percentage of animal-based food products in the daily diets increases. For example, Western diets shifted from $40 \%$ of protein originating from animal sources in the 1960 's to more than $60 \%$ today (Alexandratos and Bruinsma, 2012; Jalil, Tasoff and Bustamante, 2020). As a consequence of increasing animal-based food consumption, the demand for animal feed will increase even more. To produce $1 \mathrm{~kg}$ of animal protein, 3-6 $\mathrm{kg}$ of plant protein is needed (Alexandratos and Bruinsma, 2012). Therefore when animal-based food consumption is increasing, the need for plant-based feed is increasing even more. It is predicted that the global protein demand only for feed will reach 1500 Mton in 2050, which will be a real challenge in view of increasing food demand for the growing world population (Alexandratos and Bruinsma, 2012).

\section{Biostimulants as alternatives to enhance crop productivity}

To meet future global food demand, it is necessary to increase food production while dealing with less favourable conditions. Stresses like drought, extreme temperatures, water logging and salinity affect productivity and quality of agricultural crops. This challenge forms the basis for a new era in food production where a stable and sustainable increase of crop yield across different environments and under different conditions is key. One approach to meet these demands is to use crops that are more resilient to environmental stresses. Traditionally, breeding programs and improved cultural practices are used to increase crop resilience by producing more tolerant cultivars. However, the success rate and time required for breeding new varieties have been major challenges due to the genetic complexity of abiotic stress resilience in crops. Recently, novel alternatives to enhance crop growth such as the use of plant biostimulants have attracted researchers' attention due to their diverse applications that can enhance plant fitness. Biostimulants are 'materials other than fertilizers and pesticides' that stimulate nutritional processes independent of the crop's nutrient content with the specific aim of enhancing nutrient use efficiency, resilience to abiotic stress, quality traits, or availability of confined nutrients in the soil or rhizosphere (EU, 2019; Rouphael and Colla, 2020). These materials can 
be substances and/ or microorganisms that enhance plant growth, increase tolerance to unfavourable environmental conditions, and promote efficient use of plant resources (Yakhin et al. , 2017; Campobenedetto et al. , 2021). Biostimulants are obtained from e.g., microorganisms, plant- or animal-based by-products recycled from the food industry, or seaweed extracts.

\section{Seaweed extracts as plant biostimulants}

One of the most promising classes of biostimulants is seaweed extracts, which represents the fastest growing biostimulant industry (Markets and Markets, 2019; Carmody et al. , 2020). Seaweeds or macroalgae are multicellular marine algae that form an essential part of marine coastal ecosystems. Seaweeds are divided into three main classes based on their pigmentation, namely Phaeophyta (brown), Rhodophyta (red) and Chlorophyta (green). The extracts derived from seaweeds contain a plethora of bioactive compounds, including polysaccharides, pigments, phenolic compounds, proteins and (bioactive) peptides, phytohormones and micro- and macronutrients (Khan et al. , 2009; Craigie, 2011; Stirk and Van Staden, 2014; El Boukhari et al. , 2020).This complex chemical composition could explain the wide range of biofunctionality of these extracts. Several papers have shown the potential and advantages of using seaweed extracts as biostimulants in both normal (unstressed) and stress conditions (Khan et al. , 2009; Shukla et al. , 2019). Seaweed-derived biostimulants have great potential because: (a) seaweed extracts function in very low concentrations; (b) off-shore seaweed cultivation does not compete with land use for producing food; (c) seaweed extracts are able to increase abiotic stress resilience in many crops; and (d) the application of seaweed biostimulants can enhance protein production in protein-rich crops.

In our paper, we discuss the current status on (a) how seaweed extracts increase crop productivity under abiotic stresses, (b) the metabolite composition of seaweed-based biostimulants, (c) mechanism of action in response to biostimulant application, and (d) effect of seaweed extracts on protein production in crops. More knowledge on seaweed extracts' composition and the mode of action will optimise its use in agriculture. For example, the production process (e.g., quality of seaweed starting materials and extraction method) can be adapted according to the desired chemical composition of the resulting extract. More insight in the mode of action of specific seaweed compounds in relation to the effect on different crops will lead to targeted use of seaweed extracts and improved growth promoting effects.

\section{Seaweed extracts increase crop productivity under abiotic stresses}

Biostimulants derived from seaweed have been commercialised in recent years as substances that improve plant productivity. Under normal environmental conditions, seaweed extracts use may result in higher crop yield and productivity (Yakhin et al. , 2017; Rouphael and Colla, 2020). Field grown crops (and even sometimes, crops grown in greenhouses) are typically exposed to various stresses during their life cycle. Abiotic stresses such as drought and salinity are responsible for exorbitant crop losses, causing up to $50 \%$ reduction in crop yield as well as reducing the productivity potential of arable land (FAO and ITPS, 2015; Gull, Lone and Wani, 2019). Estimations indicate that at least $10 \%$ of total arable land are under salinisation or drought globally, with some areas simultaneously experiencing both stresses (FAO and ITPS, 2015; Shahid, Zaman and Heng, 2018; Rojas, 2020). It is therefore important to mitigate the disastrous effects of abiotic stress on crops, while improving crop productivity under these stress conditions.

Crops treated with seaweed extracts recovered from the damaging effects of heat and frost, and showed improved growth and survival under drought and saline conditions (Shukla et al. , 2019). The application of seaweed extracts reduced relative water loss and encouraged plant recovery from short-term (4 to 10 days) drought stress inArabidopsis, tomato, soybean and wheat (Santaniello et al. , 2017; Goñi, Quille and O'Connell, 2018; Shukla et al. , 2018; Sharma et al. , 2019). In these cases a reduction of leaf wilting and a significant increase in plant growth parameters were also associated with the seaweed extracts application. Chickpea plants treated with seaweed extracts prior to salinity stress exposure, showed a significant increase in vegetative growth compared to the control, saline-stressed plants not treated with seaweed extracts (Abdel Latefet al. , 2017). The same enhanced plant growth under saline conditions was also observed in wheat and rice given seaweed extracts (Zou et al., 2018; Liu et al. , 2019). 
Application of seaweed extracts in promoting vegetative growth under drought and salinisation is important but also indicating the impact seaweed extracts have on subsequent harvested crop yield and product quality under such stress conditions is even more essential to encourage adoption by farmers. One of such example is the pre-treatment of cherry tomato seeds with an Ascophyllum nodosum -based biostimulant resulting in an enhancement of fruit quality (measured as total soluble solids, lycopene and flavonoids) and up to $65 \%$ increase in crop fruit yield, even in the presence of drought stress (Murtic et al. , 2018). Similar positive results were observed in two studies of wheat grown under drought conditions. Here, foliar treatment with extracts from either Gracilaria dura or Kappaphycus spp. improved crop seed yield by $70 \%$ and $200 \%$ (doubled the initial yield) respectively (Trivedi et al., 2018; Sharma et al. , 2019). Rapeseed plants treated with any of the extracts from Ulva lactuca, Cystoseira spp or Gelidium crinale and grown either under mild $(75 \mathrm{mM}$ $\mathrm{NaCl})$ or severe $(150 \mathrm{mM} \mathrm{NaCl})$ salinity, also showed improvements (Hashem et al. , 2019). In this case, crop seed yield was up to $50 \%$ and $65 \%$ under mild and severe salt stress respectively; and a significant increase of seed oil percentage compared to the untreated plants, was also recorded (Hashem et al. , 2019). Tomato plants treated with two commercial Ascophyllum -derived extracts showed improved fruit quality under salinity stress: denoted as a significant increase in nutritional content (Di Stasio et al. , 2018).

Even though most abiotic stress experiments were performed in controlled greenhouses, positive results of seaweed extracts increasing productivity have also been translated to, and could be replicated on, farm fields (Sharma et al. , 2019). The results obtained in field experiments highlight the applicability and potential benefits of using seaweed extracts under more realistic farming conditions. In most cases, crop productivity under severe stress conditions after seaweed extracts treatment remained lower than yields under unstressed conditions (Murticet al. , 2018; Trivedi et al. , 2018; Hashem et al. , 2019). For example, salinity stress decreased crop productivity of cherry tomatoes by $50 \%$. The use of theAscophyllum nodosum -based biostimulant increased productivity by $85 \%$ of the initial crop yield under non-stressed conditions, therefore the yield gap was not fully closed (Murtic et al. , 2018). In few published cases, crops treated with seaweed extracts and grown under abiotic stress conditions showed no significant differences in crop yield (Di Stasio et al. , 2018) or even inhibitory germination responses (Masondo et al. , 2018). Thus, seaweed extracts are not always able to completely reverse or eliminate stress-induced damages, especially under severe abiotic stress. Therefore optimisation of seaweed extracts application rate (dosage and timing) for the crops, as well as insights on the underlying mechanisms may confer efficient use of the biostimulants.

\section{Metabolite composition of seaweed-based biostimulants}

Based on the source of raw materials (seaweed) and extraction method used for the production of biostimulant, seaweed extracts contain many different bioactive compounds (Shukla et al. , 2019). Furthermore, the concentration of several components in seaweeds can vary greatly over growing seasons or due to certain environmental conditions. Seasonal variation in polysaccharides, polyamines, lipids and proteins was observed in multiple seaweed species (Papenfus et al. , 2012; Khairy and El-Shafay, 2013; Fletcher et al., 2017). However, the variability in source material is mostly associated with seaweed extracts extraction from wild seaweeds since these are completely subjected to environmental conditions. Commercially available seaweed extracts often contain more than one species of seaweed since non-specific selection may occur during wild harvesting (Mac Monagailet al. , 2017). Interestingly, over the last decade there has been great progress in the field of seaweed cultivation which nowadays accounts for more than $90 \%$ of the global seaweed harvest (Little, Newton and Beveridge, 2016). Cultivation allows for controlled production of seaweeds with less influence of environmental factors resulting in a more constant chemical composition of the material. However, the cultivation of many different seaweed species has not been successful yet, including species important for the seaweed extracts industry such as the brown seaweed Ascophyllum nodosum (Shuklaet al., 2019).

Seaweed extracts are enriched in phytohormones, sterols like fucosterol, carbohydrates, polysaccharides, sugars, polyphenols like flavonoids, macro- and micronutrients, vitamins, lipids, amino acids and proteins, including enzymes (Khan et al. , 2009; Shukla et al. , 2019). Bioactive polysaccharides identified in seaweed extracts are: galactans (carrageenans and agarans) and floridean starch, ulvans, starch, lignin and cellulose, laminarin, fucoidan, and alginic acid (Shukla et al. , 2019). Most seaweed extraction methods result in 
a (partial) depolymerization of the polysaccharide pool, resulting in a dominant presence of oligo- and monosaccharides in seaweed extracts (Gullón et al. , 2020). Fucoidan oligosaccharides function as elicitors of the local defence response and as priming agents in the systemic defence of plants (Klarzynski et al. , 2003). Seaweed-derived alginates and their oligo-derivatives are reported to act in the stimulation of plant growth, development and resistance (Shukla et al. , 2019; Mukherjee and Patel, 2020). For example, foliar application of an alginate oligosaccharide (AOS) solution in a short-term hydroponic experiment ameliorated the stress caused by polyethylene glycol-induced drought in wheat (Liu et al. , 2013). Moreover, this study reported that upon application of AOS, upregulation of abscisic acid (ABA)-responsive genes that are related to drought resistance was observed (Liu et al. , 2013). Therefore, these results suggest that AOS stimulate drought resilience via the ABA-signalling pathway (Liu et al. , 2013). Together with the fact that alginate comprises up to $45 \%$ of the dry weight in brown seaweed, an important role for this (depolymerized) polysaccharide in seaweed extracts' bioactivity is implied (Vera et al. , 2011). Another polysaccharide, laminarin, has been well described as a bio-elicitor in plant defence responses against various pathogens(Romanazzi et al. , 2016; Garde-Cerdán et al. , 2017; Pugliese et al. , 2018). Additionally, laminarin oligosaccharides increased transient $\mathrm{Ca}^{2+}$ influx in the cytosol of tobacco (Nicotiana plumbaginifolia) cells. Free cytosolic $\mathrm{Ca}^{2+}$ is known to mediate a plethora of cellular processes involved in plant growth, development and resistance (Lecourieux et al. , 2002). Carrageenans and oligo-carrageenans (polysaccharides abundant in red seaweeds) also enhance growth of various plants by altering key physiological and/ or biochemical processes. These processes include photosynthesis, cell division, synthesis of nucleotide bases of purines and pyrimidines, and nitrogen-, carbon- and sulphur assimilation (Castro et al. , 2012; Gonzálezet al. , 2013; Ahmadi et al. , 2015; Shukla et al. , 2016).

Soluble alginates from seaweeds and protein hydrolysates have been reported to facilitate aggregation of soil particles, which improves the nutrient availability, aeration and water holding capacity in the soil (Khan et al. , 2009; Colla et al. , 2017). Apart from the direct benefits for the plant, seaweed extracts positively affects the soil microbiome, promoting increase of endophytes. Microbes are reported to absorb free amino acids to a higher extent than plants. In various crops it was observed that only $6 \%$ to $25 \%$ of the flagged amino acids was absorbed by the roots, while the rest was taken up by the soil microbiome (Moe, 2013). However, another study indicated that microbes excrete a substantial part of the amino acid-derived nitrogen back into the soil as ammonium, where it can be captured by the plant (Joneset al. , 2005; Jones, Nguyen and Finlay, 2009). Interestingly, Rouphael et al. , 2017 showed a synergistic effect in lettuce between a microbe-based biostimulant and a plant-based protein hydrolysate-rich extract. Crop performance was improved in the combined treatment, compared to the treatment with solely the microbe-based product. This performance was characterised by a higher total root length and surface, enhanced chlorophyll levels and an increase in nitrogen assimilation. Together this represents a strategy to ameliorate salt stress (Rouphael et al. , 2017), suggesting that general crop performance can be induced by supplementing the plant's microbiome with protein hydrolysates derived from seaweed extracts.

Many other complex organic compounds have been classified as bioactive components of seaweed extracts in various fields of application. For example polyamines have emerged as an interesting bioactive group in seaweed extracts. These compounds are present in most plants and have plant growth regulating properties (Chen et al. , 2019). Additionally, betaines are known constituents of seaweed extracts that function as cytoplasmic antioxidants or elicitors of physiological responses in the plant (Blunden et al. , 2010; MacKinnon et al. , 2010). In seaweeds, many different types of phenolic compounds have been identified and described as well. In general, brown seaweeds contain mostly phlorotannins, whereas red and green species are abundant in bromophenols, flavonoids and phenolic acid (Cotas et al. , 2020). Compared to other phenolic compounds, phlorotannins contain a higher amount of phenol rings which is associated with higher antioxidant bioactivity (Venkatesana et al. , 2020). Additionally, a group of three phenolic compounds, catechol, resorcinol and tannic acid, were reported to have an antioxidant effect in wheat when exogenously applied to the leaves (Zhao and Zou, 2002). In order to further optimize the production and application of these biostimulants, it is important to understand which compounds are responsible for the observed effects, as well as their mode of action in plants. However, it is poorly understood how these different compounds are recognized and perceived by the 
plant. Depolymerization and the degree of sulfation is associated with bioactivity of polysaccharides, thus is regarded to be of importance for the perception of these compounds (Battacharyyaet al. , 2015; Shukla et al. , 2016).

Other bioactive compounds in seaweed extracts are different pigments. Seaweed pigments are classified into three main groups: chlorophylls, carotenoids and phycobiliproteins that possess a variety of bioactive functions (Aryee, Agyei and Akanbi, 2018). Micronutrients are other compounds present in seaweed products, existing in the fresh, dried or extract form (Sharma et al. , 2014). Another group of bioactive molecules identified in seaweed extracts are plant hormones. The hormonal profile of seaweeds largely resembles that of terrestrial plants. Although their activity in seaweeds remains poorly understood, many different phytohormones have been detected including the bioactive forms of auxins, cytokinins (CK), ABA and gibberellins ( $\mathrm{Lu}$ and $\mathrm{Xu}, 2015)$. Ethylene, brassinosteroids, salicylic acid, jasmonates and strigolactones were identified in seaweed extracts as well (Stirk and Van Staden, 2014). Importantly, the presence of phytohormones in seaweed extract is not only determined by the seaweed source. Extraction and purification of phytohormones is dependent on the versatility in chemical structure and properties like water-solubility and alkalinity or acidity levels. Therefore, the presence of these bioactive compounds in the seaweed extracts depends not only on the species used, or on the extraction methods, but also on geographical location and the season in which the seaweeds were harvested (Shukla et al. , 2019).

\section{Mechanism of action in response to biostimulant application}

Seaweed extracts efficacy and its mode of action in crops have not yet been fully characterised. Seaweed extracts are thought to have specific modes of action, and mechanisms on how they may increase crop productivity and stress resilience have been proposed (Fig. 1), but linking and validating specific underlying mechanisms to crop responses due to seaweed extracts application still remains unanswered. Chemical analyses of seaweed extracts depicted bioactive components that can be linked to plant metabolic and hormone pathways. This are usually first indications, providing insight into the (possible) underlying mechanisms employed by the seaweed extracts.

Compounds in seaweed extracts may act as signaling molecules regulating key pathways at the transcriptional and/ or post-translational levels (microRNAs), causing differential expression of essential genes in crops (Fig. 1) that all together contribute to increased plant growth and abiotic stress resilience. Genes involved in cell metabolism, including lipid-, amino acid-, nucleotide- metabolism, glycolysis and transport; cell- and cell wall development were specifically modulated upon exposure to seaweed extracts in non-stress conditions (Goñi $e t$ al. , 2016). An upregulation of stress responsive genes e.g., ABA signaling regulators, $\mathrm{Na}^{+} / \mathrm{K}^{+}$transporters, late embryogenesis abundant (LEA) proteins, dehydrins and aquaporins occurred in crops under abiotic stress and treated with seaweed extracts (Muñoz-Mayor et al. , 2012; Goñi, Quille and O'Connell, 2018; Pushp S. Shukla et al. , 2018; Zou et al. , 2018; Sharma et al. , 2019). Application of an Ascophyllum -derived seaweed extracts in the presence of salinisation, stimulated expression of the microRNAs (miR) miR169g-5p, miR399, miR827 and miR2111b which results in altered expression of target genes, by this means inducing phosphate uptake and salinity resilience of Arabidopsis plants (Shukla et al. , 2018). Growth stimulation due to the application of seaweed extracts may also be linked to higher photosynthetic rates and corresponding increased levels of chlorophyll pigments (chlorophyll a, b and carotenoids) in such crops, relative to their nontreated and abiotic stressed counterparts (Abdel Latef et al. , 2017; Murtic et al. , 2018; Trivedi et al. , 2018; Hussein et al. , 2021). Mediating the activity of enzymes and genes involved in efficient nutrient assimilation (Fig. 1b, d) is another proposed mode of action that contributes to overall increased growth (Goñi et al. , 2016; Yakhin et al. , 2017; Shukla et al. , 2019). Crops treated with seaweed extracts accumulate more macroand micro-elements, as well as carbohydrates, proteins and vitamins independent of the presence or absence of stress (Di Stasio et al. , 2018; Trivedi et al. , 2018; Hussein et al. , 2021). Furthermore, higher production of phenolic acids such as flavonoids e.g., naringenin and rutin in tomato, are stimulated by seaweed extracts treatment (Fig. 1b, d) leading to enhanced fruit colouring and flavour profile of the crops (Murticet al. , 2018; Shukla et al. , 2019).

Modulation of hormone pathways due to seaweed extract application promote plant growth and develop- 
ment under both stress and unstressed conditions (Fig. 1d). Derivatives of the phytohormones ABA, auxin e.g., indole-3-acetic acid (IAA) and indole-3-butyric acid (IBA), CK e.g., benzyl adenine (BA) and zeatin, gibberellin e.g., gibberellic acid (GA3), and jasmonic acid were further induced in rapeseed plants treated with certain seaweed extracts and exposed to salinity stress (Hashemet al. , 2019). Additionally, seaweed extracts alleviate abiotic stresses by increasing antioxidant activity of reactive oxygen species (ROS) scavenging enzymes e.g., superoxide dismutase, peroxidases, catalases and phenolic antioxidants (Abdel Latef et al. , 2017; El Boukhari et al. , 2020; Hussein et al. , 2021). This leads to a reduction in ROS accumulation (Fig. 1d), observed as decreased $\mathrm{H}_{2} \mathrm{O}_{2}$ levels and reduced accumulation of lipid peroxidation, measured as the malondialdehyde content (Abdel Latefet al. , 2017; Goñi, Quille and O'Connell, 2018; Trivedi et al. , 2018). The accumulation of osmo-protectants such as proline, sugars and organic acids also occur due to the application of seaweed extracts (Fig. 1d). Drought and salt-exposed plants treated with seaweed extracts show increased proline and sugar (glucose, fructose and sucrose) levels (Goñi, Quille and O'Connell, 2018) that serve as osmolytes essential for maintaining osmotic balance during the stress (Singh et al. , 2015).

Of importance is that small differences in the components of extracts derived from the same seaweed species may still lead to much bigger variation at the molecular or cellular level and in overall crop responses, in crops where these seaweed extracts are applied (Goñiet al. , 2016; Ertani et al. , 2018). Thus, generalisations on the mode of action (and resulting benefits) of the seaweed extracts should not be made, rather independent experiments must be performed to confirm hypotheses. Most of the strategies discussed in the paragraphs above are typically employed by plants during their life cycle, including the activation of specific pathways to cope with abiotic stress (Zhu, 2016, Fig. 1c). Moreover, a lot of cross-talk occurs between signaling pathways, therefore application of seaweed extracts may induce and/ or repress multiple pathways or metabolic processes simultaneously. Hence, this presents one of the difficulties in deciphering and characterising specific underlying mechanisms employed by seaweed extracts. Although the presence of phycocolloids e.g., alginates and carrageenans in seaweed extracts, that are otherwise absent in land plants, support the argument that these extracts have a unique mode of action, it is still possible that the application of a single seaweed-based extract may have broad spectrum additive impact on crops, modulating several response mechanisms to stimulate growth and survival of plants in both stressed and unstressed conditions. Overall, further research in this direction is still needed to make concrete inferences. Understanding exactly how the underlying mechanisms function is key for increasing seaweed extracts effectivity and efficiency, to improve crop performance under abiotic stress in the field.

\section{Effect of seaweed extracts on protein production in crops}

Global seaweed production has risen exponentially in recent decades to 30 Mton annually. Moreover, apart from their potential as a direct food source for humans and animals, seaweed extracts were not only shown to boost abiotic stress resistance in crops but also to increase its nutritional value (Shukla et al. , 2019). Overall crop yield could be increased by application of seaweed extracts as biostimulants under normal and stress conditions. Here we summarise (Table 1) that seaweed extracts can also increase protein productivity in crops. Several reports showed that seaweed extracts increased the crude protein content in plant families like Fabaceae and Poaceae. The highest increase in protein content by two-fold ( $200 \%)$ was reported in Vigna sinensis (Table 1). Considerable protein increase was shown as well in Triticum aestivum, Musa spp.and Allium cepa (Table 1). An explanation for the increased protein content is the amplified plant uptake of more essential nutrients for protein production, that may be due to enhanced root systems because of the seaweed extracts application as reported in Sivasankari et al. (Sivasankari et al. , 2006). Alteration of the root system and increased nutrient assimilation in crops have also been reported during abiotic stress (Shukla et al. , 2019; El Boukhariet al. , 2020; Campobenedetto et al. , 2021), so there is a potential of increased protein productivity during abiotic stress. However, whether seaweed extracts improve root system and therefore crop protein productivity under adverse conditions remains unanswered, since all the experiments (Table 1) were only performed under non-stressed conditions.

These findings suggest that for future agricultural practices, we can use seaweed biostimulants to increase crop yield by increasing per acre the nutritional value and protein content in crops. 


\section{Perspective}

Today there are many commercial seaweed biostimulants available for agricultural use (Khan et al. , 2009; Shukla et al. , 2019), so the basis for a broad use of seaweed extracts is already created. Although the effectiveness of many of these extracts have been proven, especially under experimentally controlled conditions, not all mechanisms of action have been revealed (Shukla et al. , 2019). In addition, more field trials testing the optimal concentrations of extracts for different crops and under varied soil conditions should be carried out. Future field experiments should also address the business case i.e., how many seaweed extracts applications are needed and what is the return on investment. Also, these experiments may, in combination with seaweed extracts factory production data, give insight in which direction large-scale commercial seaweed production should evolve. Further elaboration on the question whether 'seaweeds should be cultivated to stimulate productivity of arable crops under normal and unstressed conditions, or are they more beneficial as direct food source for humans?' remains of interest. We advocate that less seaweed cultivation surface area is needed to finally produce similar or more protein productivity in arable crops after seaweed extracts application, compared to direct seaweed (protein) consumption.

Crops grown in the field are realistically exposed to different stresses at the same time. Application of several extracts together, or at specific timepoints, may moderate the impact of multiple stresses on crops. Furthermore, the multifunctionality of seaweed extracts should be explored since a single extract often induces several plant stress signaling pathways. More research is needed to investigate if the beneficial effects of the seaweed extracts will increase when combined with other non-seaweed derived biostimulants e.g., microbial biostimulants, or even with fertilizers and manures. Insight into the mode of action and which seaweed extracts compounds are essential for these interactions will enable seaweed extracts product improvement.

Overall, seaweed biostimulants have numerous positive effects on plant growth and thus have the potential to solve some of the problems agriculture will face in the future. Our findings suggest that future agricultural practices can make use of seaweed-based biostimulants to increase crop yield, nutritional value and protein content per acre, including in crops grown on marginal lands currently subject to severe drought and salinity. In this way seaweed extracts can contribute to an increased annual global protein productivity, without increasing arable land use at the cost of precious natural habitat and biodiversity. The application of seaweed extracts to improve soil quality (Shukla et al. , 2019) may be further explored as a potential solution for soil recovery or to facilitate bioremediation.

\section{Author Contributions}

A.O.D.-A., I.M.vdM., R.K. collected the data and wrote the original manuscript. A.O.D.-A., I.M.vdM., A.vdW., R.K. reviewed and edited the manuscript. All authors have read and agreed to the published version of the manuscript.

\section{Funding}

This work is supported by the Wageningen University \& Research community-funded project, Protein Transition Investment Theme (to I. M.vdM., A.vdW. and R.K.). Funds from Knowledge Base project (KB34-007004) by the Dutch Ministry of Agriculture, Nature and Food Quality (to I.M.vdM., A.vdW. and A.O.D.-A.) also supported this work.

\section{Acknowledgments}

We thank Morris Mes for making the digital illustrations of Figure 1. We are grateful to Berend Groutars for his helpful comments and discussion on the manuscript.

\section{Conflicts of Interest}

There is no conflict of interest.

\section{References}


Abdel Latef, A. A. H. et al. (2017) 'Sargassum muticum and Jania rubens regulate amino acid metabolism to improve growth and alleviate salinity in chickpea', Scientific Reports . Springer US, 7, p. 10537. doi: 10.1038/s41598-017-07692-w.

Ahmadi, A. et al. (2015) 'Antiviral potential of algae polysaccharides isolated from marine sources: A review', BioMed Research International . Hindawi Publishing Corporation, 825203. doi: 10.1155/2015/825203.

Alexandratos, N. and Bruinsma, J. (2012) World Agriculture Towards 2030/2050: The 2012 Revision, ESA Working Paper No. 12-03 . Rome. doi: 10.1002/jso.2930300113.

Aryee, A. N., Agyei, D. and Akanbi, T. O. (2018) 'Recovery and utilization of seaweed pigments in food processing', Current Opinion in Food Science . Elsevier Ltd, 19, pp. 113-119. doi: 10.1016/j.cofs.2018.03.013.

Battacharyya, D. et al. (2015) 'Seaweed extracts as biostimulants in horticulture', Scientia Horticulturae, 196, pp. 39-48. doi: 10.1016/j.scienta.2015.09.012.

Blunden, G. et al. (2010) 'Betaine yields from marine algal species utilized in the preparation of seaweed extracts used in agriculture', Natural Product Communications , 5(4), pp. 581-585. doi: $10.1177 / 1934578 \times 1000500418$.

El Boukhari, M. E. M. et al. (2020) 'Trends in Seaweed Extract Based Biostimulants: Manufacturing Process and Beneficial Effect on Soil-Plant Systems', Plants, 9, p. 359.

Campobenedetto, C. et al. (2021) 'The application of a biostimulant based on tannins affects root architecture and improves tolerance to salinity in tomato plants', Scientific Reports . Nature Publishing Group UK, 11, p. 354. doi: 10.1038/s41598-020-79770-5.

Carmody, N. et al. (2020) 'Ascophyllum nodosum Extract Biostimulant Processing and Its Impact on Enhancing Heat Stress Tolerance During Tomato Fruit Set', Frontiers in Plant Science, 11, p. 807. doi: 10.3389/fpls.2020.00807.

Castro, J. et al. (2012) 'Oligo-Carrageenans Stimulate Growth by Enhancing Photosynthesis, Basal Metabolism, and Cell Cycle in Tobacco Plants (var. Burley)', Journal of Plant Growth Regulation, 31, pp. 173-185. doi: 10.1007/s00344-011-9229-5.

Chen, D. et al. (2019) 'Polyamine function in plants: Metabolism, regulation on development, and roles in abiotic stress responses',Frontiers in Plant Science , 9, p. 1945. doi: 10.3389/fpls.2018.01945.

Colla, G. et al. (2017) 'Biostimulant action of protein hydrolysates: Unraveling their effects on plant physiology and microbiome', Frontiers in Plant Science, 8, p. 2202. doi: 10.3389/fpls.2017.02202.

Cotas, J. et al. (2020) 'Seaweed Phenolics: From Extraction to Applications', Marine Drugs , 18, p. 384.

Craigie, J. S. (2011) 'Seaweed extract stimuli in plant science and agriculture', Journal of Applied Phycology , 23, pp. 371-393. doi: 10.1007/s10811-010-9560-4.

Ertani, A. et al. (2018) 'Evaluation of seaweed extracts from laminaria and ascophyllum nodosum spp. As biostimulants in zea mays L. using a combination of chemical, biochemical and morphological approaches', Frontiers in Plant Science, 9, p. 428. doi: 10.3389/fpls.2018.00428.

EU (2019) 'Regulation ofthe european parliament and ofthe council laying down rules on the making available on the market of EU fertilising products and amending Regulations (EC) No 1069/2009 and (EC) No 1107/2009 and repealing Regulation (EC) No 2003/2003', Official Journal of the European Union. Available at: https://eur-lex.europa.eu/legal-content/EN/TXT/PDF/?uri=CELEX:32019R1009\&from=EN.

FAO and ITPS (2015) Status of the World's Soil Resources (SWSR)- Main Report, Food and Agriculture Organization of the United Nations and Intergovernmental Technical Panel on Soils . Rome, Italy. Available at: http://www.fao.org/3/a-i5199e.pdf. 
Fletcher, H. R. et al. (2017) 'The seasonal variation of fucoidan within three species of brown macroalgae', Algal Research . The Authors, 22, pp. 79-86. doi: 10.1016/j.algal.2016.10.015.

Garde-Cerdán, T. et al. (2017) 'Chitosan and Laminarin as Alternatives to Copper for Plasmopara viticola Control: Effect on Grape Amino Acid', Journal of Agricultural and Food Chemistry, 65(34), pp. 7379-7386. doi: $10.1021 /$ acs.jafc.7b02352.

Goñi, O. et al. (2016) 'Comparative Transcriptome Analysis of Two Ascophyllum nodosum Extract Biostimulants: Same Seaweed but Different', Journal of Agricultural and Food Chemistry, 64, pp. 2980-2989. doi: 10.1021/acs.jafc.6b00621.

Goñi, O., Quille, P. and O'Connell, S. (2018) 'Ascophyllum nodosum extract biostimulants and their role in enhancing tolerance to drought stress in tomato plants', Plant Physiology and Biochemistry . Elsevier, 126, pp. 63-73. doi: 10.1016/j.plaphy.2018.02.024.

González, A. et al. (2013) 'Seaweed Oligosaccharides Stimulate Plant Growth by Enhancing Carbon and Nitrogen Assimilation, Basal Metabolism, and Cell Division', Journal of Plant Growth Regulation, 32, pp. 443-448. doi: 10.1007/s00344-012-9309-1.

Gull, A., Lone, A. A. and Wani, N. U. I. (2019) 'Biotic and Abiotic Stresses in Plants', IntechOpen, p. 85832. doi: http://dx.doi.org/10.5772/57353.

Gullón, B. et al. (2020) 'Seaweeds as promising resource of bioactive compounds: Overview of novel extraction strategies and design of tailored meat products', Trends in Food Science and Technology . Elsevier, 100, pp. 1-18. doi: 10.1016/j.tifs.2020.03.039.

Hashem, H. A. et al. (2019) 'The potentiality of marine macro-algae as bio-fertilizers to improve the productivity and salt stress tolerance of canola (Brassica napus L.) plants', Agronomy, 9, p. 146. doi: 10.3390/agronomy9030146.

Henchion, M. et al. (2014) 'Meat consumption: Trends and quality matters', Meat Science . Elsevier Ltd, 98, pp. 561-568. doi: $10.1016 /$ j.meatsci.2014.06.007.

Hidangmayum, A. and Sharma, R. (2017) 'Effect of different concentrations of commercial seaweed liquid extract of Ascophyllum nodosum as a plant bio stimulant on growth, yield and biochemical constituents of onion (Allium cepa L.)', Journal of Pharmacognosy and Phytochemistry , 6(4), pp. 658-663.

Hussein, M. H. et al. (2021) 'Seaweed extracts as prospective plant growth bio-stimulant and salinity stress alleviator for Vigna sinensis and Zea mays', Journal of Applied Phycology . Journal of Applied Phycology, 33, pp. 1273-1291. doi: 10.1007/s10811-020-02330-x.

Jalil, A. J., Tasoff, J. and Bustamante, A. V. (2020) 'Eating to save the planet: Evidence from a randomized controlled trial using individual-level food purchase data', Food Policy . Elsevier, 95, p. 101950. doi: 10.1016/j.foodpol.2020.101950.

Jones, D. L. et al. (2005) 'Dissolved organic nitrogen uptake by plants - An important N uptake pathway?', Soil Biology and Biochemistry, 37, pp. 413-423. doi: 10.1016/j.soilbio.2004.08.008.

Jones, D. L., Nguyen, C. and Finlay, R. D. (2009) 'Carbon flow in the rhizosphere: Carbon trading at the soil-root interface', Plant and Soil , 321, pp. 5-33. doi: 10.1007/s11104-009-9925-0.

Jothinayagi, N. and Anbazhagan, C. (2009) 'Effect of Seaweed Liquid Fertilizer of Sargassum wightii on the Growth and Biochemical Characteristics of Abelmoschus esculentus (L.) Medikus', Recent Research in Science and Technology , 1(4), pp. 155-158.

Karthikeyan, K. and Shanmugam, M. (2016) 'Grain Yield and Functional Properties of Red Gram Applied With Seaweed Extract Powder Manufactured From Kappaphycus Alvarezii', International Journal of Recent Advances in Multidisciplinary Research, 3(3), pp. 1353-1359. 
Khairy, H. M. and El-Shafay, S. M. (2013) 'Seasonal variations in the biochemical composition of some common seaweed species from the coast of Abu Qir Bay, Alexandria, Egypt', Oceanologia . Elsevier Masson SAS, 55(2), pp. 435-452. doi: 10.5697/oc.55-2.435.

Khan, W. et al. (2009) 'Seaweed extracts as biostimulants of plant growth and development', Journal of Plant Growth Regulation , 28, pp. 386-399. doi: 10.1007/s00344-009-9103-x.

Klarzynski, O. et al. (2003) 'Sulfated fucan oligosaccharides elicit defense responses in tobacco and local and systemic resistance against tobacco mosaic virus', Molecular Plant-Microbe Interactions , 16(2), pp. 115-122. doi: 10.1094/MPMI.2003.16.2.115.

Kocira, S. et al. (2018) 'Modeling biometric traits, yield and nutritional and antioxidant properties of seeds of three soybean cultivars through the application of biostimulant containing seaweed and amino acids', Frontiers in Plant Science, 9, p. 388. doi: 10.3389/fpls.2018.00388.

Kulkarni, M. G. et al. (2019) 'Bioactive molecules derived from smoke and seaweed Ecklonia maxima showing phytohormone-like activity in Spinacia oleracea L.', New Biotechnology , 48, pp. 83-89. doi: 10.1016/j.nbt.2018.08.004.

Layek, J. et al. (2018) 'Seaweed extract as organic bio-stimulant improves productivity and quality of rice in eastern Himalayas', Journal of Applied Phycology , 30, pp. 547-558. doi: 10.1007/s10811-017-1225-0.

Lecourieux, D. et al. (2002) 'Analysis and effects of cytosolic free calcium increases in response to elicitors in Nicotiana plumbaginifolia cells', Plant Cell , 14, pp. 1-15. doi: 10.1105/tpc.005579.

Little, D. C., Newton, R. W. and Beveridge, M. C. M. (2016) 'Aquaculture: A rapidly growing and significant source of sustainable food? Status, transitions and potential', Proceedings of the Nutrition Society, 75, pp. 274-286. doi: 10.1017/S0029665116000665.

Liu, H. et al. (2013) 'Alginate oligosaccharides enhanced Triticum aestivum L. tolerance to drought stress', Plant Physiology and Biochemistry . Elsevier Masson SAS, 62, pp. 33-40. doi: 10.1016/j.plaphy.2012.10.012.

Liu, H. et al. (2019) 'Polysaccharides from Grateloupia filicina enhance tolerance of rice seeds (Oryza sativa L.) under salt stress',International Journal of Biological Macromolecules . Elsevier B.V., 124, pp. 1197-1204. doi: 10.1016/j.ijbiomac.2018.11.270.

$\mathrm{Lu}, \mathrm{Y}$. and $\mathrm{Xu}$, J. (2015) 'Phytohormones in microalgae: A new opportunity for microalgal biotechnology?', Trends in Plant Science . Elsevier Ltd, 20(5), pp. 273-282. doi: 10.1016/j.tplants.2015.01.006.

MacKinnon, S. L. et al. (2010) 'Improved methods of analysis for betaines in Ascophyllum nodosum and its commercial seaweed extracts', Journal of Applied Phycology , 22, pp. 489-494. doi: 10.1007/s10811-009-94830 .

Markets and Markets (2019) Biostimulants Market by Active Ingredient (Humic Substances, Amino Acids, Seaweed Extracts, Microbial Amendments), Crop Type (Fruits \& Vegetables, Cereals, Turf 83 Ornamentals), Application Method, Form, and Region - Global Forecast to 2025. Available at: https://www.marketsandmarkets.com/Market-Reports/biostimulant-market-1081.html (Accessed: 21 May 2021).

Masondo, N. A. et al. (2018) 'Influence of biostimulants-seed-priming on Ceratotheca triloba germination and seedling growth under low temperatures, low osmotic potential and salinity stress', Ecotoxicology and Environmental Safety , 147, pp. 43-48. doi: 10.1016/j.ecoenv.2017.08.017.

Moe, L. A. (2013) 'Amino acids in the rhizosphere: From plants to microbes', American Journal of Botany , 100(9), pp. 1-14. doi: 10.3732/ajb.1300033.

Mac Monagail, M. et al. (2017) 'Sustainable harvesting of wild seaweed resources', European Journal of Phycology . Taylor \& Francis, 52(4), pp. 371-390. doi: 10.1080/09670262.2017.1365273. 
Mueller, N. D. et al. (2012) 'Closing yield gaps through nutrient and water management', Nature . Nature Publishing Group, 490, pp. 254-257. doi: 10.1038/nature11420.

Mukherjee, A. and Patel, J. S. (2020) 'Seaweed extract: biostimulator of plant defense and plant productivity', International Journal of Environmental Science and Technology . Springer Berlin Heidelberg, 17, pp. 553558. doi: 10.1007/s13762-019-02442-z.

Muñoz-Mayor, A. et al. (2012) 'Overexpression of dehydrin tas14 gene improves the osmotic stress imposed by drought and salinity in tomato', Journal of Plant Physiology , 169, pp. 459-468. doi: 10.1016/j.jplph.2011.11.018.

Murtic, S. et al. (2018) 'Effects of seaweed extract on the growth, yield and quality of cherry tomato under different growth conditions', Acta Agriculturae Slovenica , 111(2), pp. 315-325. doi: 10.14720/aas.2018.111.2.07.

Papenfus, H. B. et al. (2012) 'Seasonal variation in the polyamines of Ecklonia maxima', Botanica Marina, 55(5), pp. 539-546. doi: 10.1515/bot-2012-0150.

Pugliese, M. et al. (2018) 'Application of laminarin and calcium oxide for the control of grape powdery mildew on Vitis vinifera cv. Moscato', Journal of Plant Diseases and Protection . Springer Berlin Heidelberg, 125, pp. 477-482. doi: 10.1007/s41348-018-0162-8.

Rengasamy, K. R. R. et al. (2016) 'Enhancing growth, phytochemical constituents and aphid resistance capacity in cabbage with foliar application of eckol - a biologically active phenolic molecule from brown seaweed', New Biotechnology . Elsevier B.V., 33, pp. 273-279. doi: 10.1016/j.nbt.2015.11.002.

Rojas, O. (2020) 'Agricultural extreme drought assessment at global level using the FAO-Agricultural Stress Index System (ASIS)', Weather and Climate Extremes . Elsevier B.V., 27, p. 100184. doi: 10.1016/j.wace.2018.09.001.

Romanazzi, G. et al. (2016) 'Impact of alternative fungicides on grape downy mildew control and vine growth and development', Plant Disease, 100(4), pp. 739-748. doi: 10.1094/PDIS-05-15-0564-RE.

Rouphael, Y. et al. (2017) 'Synergistic action of a microbial-based biostimulant and a plant derived-protein hydrolysate enhances lettuce tolerance to alkalinity and salinity', Frontiers in Plant Science , 8, p. 131. doi: 10.3389/fpls.2017.00131.

Rouphael, Y. and Colla, G. (2020) 'Editorial: Biostimulants in Agriculture', Frontiers in Plant Science, 11, p. 40. doi: $10.3389 /$ fpls.2020.00040.

Santaniello, A. et al. (2017) 'Ascophyllum nodosum seaweed extract alleviates drought stress in Arabidopsis by affecting photosynthetic performance and related gene expression', Frontiers in Plant Science, , 8, p. 1362. doi: $10.3389 /$ fpls.2017.01362.

Shah, M. T. et al. (2013) 'Seaweed Sap As an Alternative Liquid Fertilizer for Yield and Quality Improvement of Wheat', Journal of Plant Nutrition, 36, pp. 192-200. doi: 10.1080/01904167.2012.737886.

Shahid, S. A., Zaman, M. and Heng, L. (2018) 'Soil Salinity: Historical Perspectives and a World Overview of the Problem', in Zaman, M., Shahid, S. A., and Heng, L. (eds) Guideline for Salinity Assessment, Mitigation and Adaptation Using Nuclear and Related Techniques. Switzerland: Springer Nature, pp. 43-54.

Sharma, H. S. S. et al. (2014) 'Plant biostimulants: A review on the processing of macroalgae and use of extracts for crop management to reduce abiotic and biotic stresses', Journal of Applied Phycology, 26, pp. 465-490. doi: 10.1007/s10811-013-0101-9.

Sharma, S. et al. (2019) 'Gracilaria dura extract confers drought tolerance in wheat by modulating abscisic acid homeostasis', Plant Physiology and Biochemistry . Elsevier, 136, pp. 143-154. doi: 10.1016/j.plaphy.2019.01.015. 
Shukla, P. S. et al. (2016) 'Carrageenans from red seaweeds as promoters of growth and elicitors of defense response in plants',Frontiers in Marine Science, 3, p. 81. doi: 10.3389/fmars.2016.00081.

Shukla, Pushp Sheel et al. (2018) 'Ascophyllum nodosum extract mitigates salinity stress in Arabidopsis thaliana by modulating the expression of miRNA involved in stress tolerance and nutrient acquisition', PLoS ONE , 13(10), p. e0206221. doi: 10.1371/journal.pone.0206221.

Shukla, Pushp S. et al. (2018) 'Seaweed extract improve drought tolerance of soybean by regulating stressresponse genes', AoB PLANTS , 10, p. plx051. doi: 10.1093/aobpla/plx051.

Shukla, P. S. et al. (2019) 'Ascophyllum nodosum-based biostimulants: Sustainable applications in agriculture for the stimulation of plant growth, stress tolerance, and disease management',Frontiers in Plant Science, 10, p. 655. doi: 10.3389/fpls.2019.00655.

Singh, M. et al. (2015) 'Roles of osmoprotectants in improving salinity and drought tolerance in plants: a review', Reviews in Environmental Science and Biotechnology . Springer Netherlands, 14, pp. 407-426. doi: 10.1007/s11157-015-9372-8.

Sivasankari, S. et al. (2006) 'Effect of seaweed extracts on the growth and biochemical constituents of Vigna sinensis',Bioresource Technology , 97, pp. 1745-1751. doi: 10.1016/j.biortech.2005.06.016.

Di Stasio, E. et al. (2018) 'Ascophyllum nodosum-based algal extracts act as enhancers of growth, fruit quality, and adaptation to stress in salinized tomato plants', Journal of Applied Phycology . Journal of Applied Phycology, 30, pp. 2675-2686. doi: 10.1007/s10811-018-1439-9.

Stirk, W. A. and Van Staden, J. (2014) Plant growth regulators in seaweeds: Occurrence, regulation and functions, Advances in Botanical Research: Sea Plants . Edited by N. Bourgougnon. London, UK: Elsevier. doi: 10.1016/B978-0-12-408062-1.00005-6.

Trivedi, K. et al. (2018) 'Drought alleviatory potential of Kappaphycus seaweed extract and the role of the quaternary ammonium compounds as its constituents towards imparting drought tolerance in Zea mays L.', Journal of Applied Phycology . Journal of Applied Phycology, 30, pp. 2001-2015. doi: 10.1007/s10811-017$1375-0$.

UN DESA (2017) World population projected to reach 9.8 billion in 2050, and 11.2 billion in 2100 . Available at: https://www.un.org/development/desa/en/news/population/world-population-prospects-2017.html (Accessed: 15 May 2020).

Venkatesana, J. et al. (2020) 'Phlorotannins', Encyclopedia of Food Chemistry, 3, pp. 515-527.

Vera, J. et al. (2011) 'Seaweed polysaccharides and derived oligosaccharides stimulate defense responses and protection against pathogens in plants', Marine Drugs , 9, pp. 2514-2525. doi: 10.3390/md9122514.

Yakhin, O. I. et al. (2017) 'Biostimulants in plant science: A global perspective', Frontiers in Plant Science , 7, p. 2049. doi: 10.3389/fpls.2016.02049.

Zhao, H. J. and Zou, Q. (2002) 'Protective effects of exogenous antioxidants and phenolic compunds on photosynthesis of wheat leaves under irradiance and oxidative stress', Photosynthetica , 40(4), pp. 523-527.

Zhu, J.-K. (2016) 'Abiotic Stress Signaling and Responses in Plants', Cell . Elsevier, 167, pp. 313-324. doi: 10.1016/j.cell.2016.08.029.

Zodape, S. T. et al. (2011) 'Foliar application of seaweed sap as biostimulant for enhancement of yield and quality of tomato (Lycopersicon esculentum Mill.)', Journal of Scientific 83 Industrial Research, 70, pp. 215-219. doi: 10.1115/DETC2010-29226.

Zou, P. et al. (2018) 'Low-molecular-weightt polysaccharides from Pyropia yezoensis enhance tolerance of wheat seedlings (Triticum aestivum L.) to salt stress', Frontiers in Plant Science , 9, p. 427. doi: $10.3389 /$ fpls.2018.00427. 


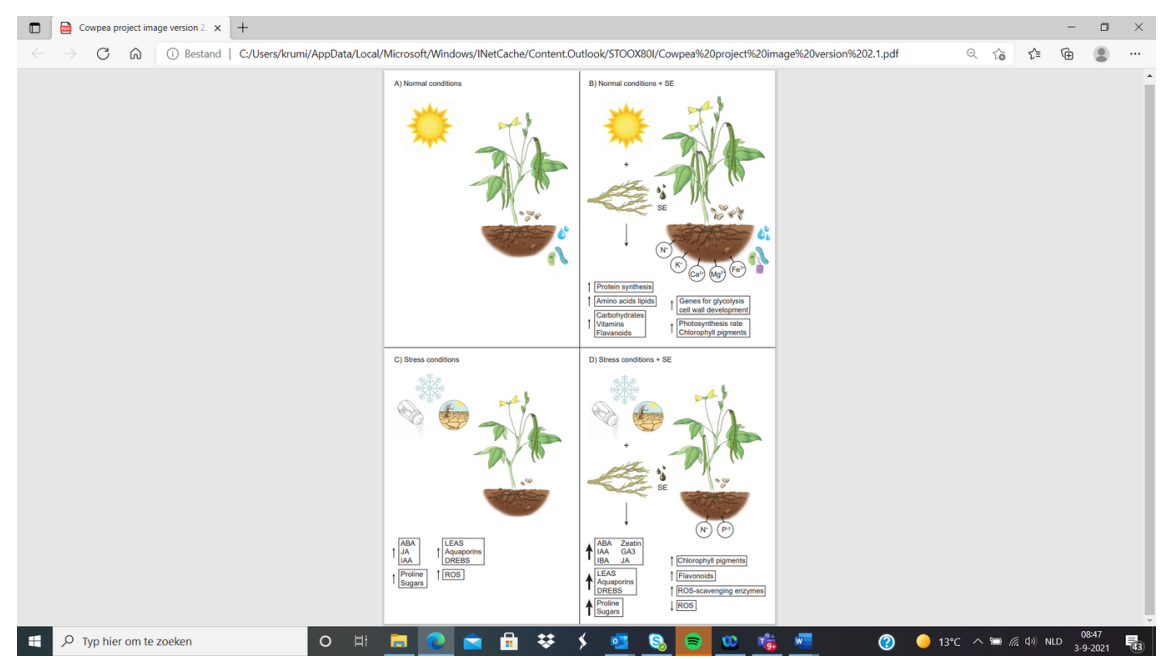

Figure 1. Underlying mechanism of action under (a)normal conditions and (b) normal conditions with the application of seaweed extracts (SE). Under normal (unstressed) conditions, seaweed extracts stimulate a number of processes resulting in improved crop growth and productivity. Seaweed extracts facilitate assimilation of both macro- and micronutrients e.g., $\mathrm{N}$ (nitrogen), K (potassium), Ca (calcium), Mg (magnesium) and $\mathrm{Fe}$ (iron). Alginates present in seaweed extracts improve soil quality and structure by boosting water retention, air circularity and promoting endophyte activity. Seaweed extracts induce genes/ enzymes involved in cell wall biosynthesis and photosynthesis. Induction of other genes/ enzymes of important metabolic pathways by seaweed extracts result in higher crop protein, amino acid, lipid, carbohydrate, vitamin, flavonoid, chlorophyll and carotene content. Proposed mechanism of action in response to (c) abiotic stress conditions and (d)abiotic stress conditions with seaweed extracts' application. Under abiotic stresses like salinity, drought and freezing, seaweed extracts mediate certain metabolic processes resulting in improved crop resilience and growth under the stress. Seaweed extracts cause up/ down-regulation of transcription factors (TFs), microRNAs and genes involved in maintaining $\mathrm{N}$ and $\mathrm{P}$ (phosphorus) homeostasis. The application of seaweed extracts to crops increase the levels of the phytohormone ABA (abscisic acid) and hormonal derivatives IAA (indole-3-acetic acid), IBA (indole-3-butyric acid), zeatin, GA3 (gibberellic acid) and JA (jasmonic acid). Stress responsive dehydration responsive element binding (DREB) TFs, late embryogenesis abundant (LEA) proteins and aquaporins are further induced in the presence of seaweed extracts. Osmotic balance is maintained by further accumulation of osmo-protectants like proline and sugars, by the seaweed extracts. The extracts have a positive effect on chlorophyll pigment and flavonoid accumulation. Reactive oxygen species (ROS) production is inhibited upon treatment with seaweed extracts.

Table 1. Seaweed extracts increase protein content in crops.

\begin{tabular}{llll}
\hline Source & Seaweed specie & Crop & Concentration of seawe \\
\hline (Hidangmayum and Sharma, 2017) & Ascophyllum nodosum & Allium cepa & $0,55 \%$ \\
(Kocira et al., 2018) & Ascophyllum nodosum & Glycine max L. (Annushka) & $0,70 \%$ \\
(Kocira et al., 2018) & Ascophyllum nodosum & Glycine max L. (Atlanta) & $0,70 \%$ \\
(Kocira et al., 2018) & Ascophyllum nodosum & Glycine max L. (Mavka) & $1,00 \%$ \\
(Kulkarni et al., 2019) & Ecklonia maxima & Spinacea oleracea L & $0,40 \%$ \\
(Rengasamy et al., 2016) & Ecklonia maxima & Brassica oleracea & $0,40 \%$ \\
(Sivasankari et al., 2006) & Caulerpa chemnitzia & Vigna sinensis & $20,00 \%$ \\
(Sivasankari et al., 2006) & Sargassum wightii & Vigna sinensis & $20,00 \%$ \\
(Jothinayagi and Anbazhagan, 2009) & Sargassum wightii & Abelmoschus esculentus & $20,00 \%$ \\
(Shah et al., 2013) & Kapaphycus alvarezii & Triticum aestivum & $7,50 \%$ \\
(Shah et al., 2013) & Gracilaria edulis & Triticum aestivum & $7,50 \%$
\end{tabular}




\begin{tabular}{llll}
\hline Source & Seaweed specie & Crop & Concentration of seawe \\
\hline (Layek et al., 2018) & Gracilaria edulis & Oryza sativa & $15,00 \%$ \\
(Layek et al., 2018) & Kapaphycus alvarezii & Oryza sativa & $15,00 \%$ \\
(Karthikeyan and Shanmugam, 2016) & Kapaphycus alvarezii & Musa spp. (Robusta) & $5,00 \%$ \\
(Karthikeyan and Shanmugam, 2016) & Kapaphycus alvarezii & Musa spp. (Njali poovan) & $5,00 \%$ \\
(Karthikeyan and Shanmugam, 2016) & Kapaphycus alvarezii & Musa spp. (Red banana) & $5,00 \%$ \\
(Karthikeyan and Shanmugam, 2016) & Kapaphycus alvarezii & Musa spp. (Nendran) & $5,00 \%$ \\
(Zodape et al., 2011) & Kapaphycus alvarezii & Vigna radiata & $10,00 \%$ \\
\hline
\end{tabular}

\section{Hosted file}

Figure1.pdf available at https://authorea.com/users/437344/articles/539045-the-power-ofseaweeds-as-plant-biostimulants-to-boost-crop-production-under-abiotic-stress 